\title{
Produção e nutrição mineral do maracujazeiro-amarelo em solo com biofertilizante supermagro e potássio ${ }^{1}$
}

\author{
Artenisa C. Rodrigues $^{2}$, Lourival F. Cavalcante ${ }^{3}$, Ademar P. de Oliveira ${ }^{4}$, José T. de Sousa ${ }^{5} \&$ Francisco O. Mesquita $^{6}$
}

\begin{abstract}
RESUMO
Um experimento foi conduzido no período de dezembro/2005 a julho/2006, no município de Remígio, PB, com o objetivo de se avaliar a ação do biofertilizante supermagro aplicado ao solo após diluição em água, na proporção de 1:4, na ausência e presença de potássio, sobre a produção e nutrição mineral do maracujazeiro-amarelo (Passiflora edulis f. flavicarpa Deg). O delineamento estatístico foi blocos ao acaso em esquema fatorial (5 $\times 2$ ), sendo cinco doses de biofertilizante $\left(0,1,2\right.$, 3 e $4 \mathrm{~L}$ planta ${ }^{-1}$ da mistura), na ausência e presença de potássio $\left(\mathrm{K}_{2} \mathrm{O}\right)$. O supermagro foi aplicado 30 dias antes e a cada 90 dias após o plantio e o potássio aos 60 dias após o plantio e a cada 60 dias até a colheita. O solo da área experimental é um Cambissolo Húmico Aluminoférrico léptico. Semanalmente, os frutos foram contados e pesados, não só para avaliação da quantidade mas, também, para obtenção de sua produção por planta, massa média de frutos e produtividade; no início da frutificação as plantas estavam adequadamente supridas de N, K, S, B e Zn mas deficientes em $\mathrm{P}, \mathrm{Ca}, \mathrm{Mg}$, Cu, Fe e Mn. A massa média de frutos foi superior nas plantas dos tratamentos com supermagro e potássio, porém a produtividade não foi influenciada pela interação supermagro versus potássio.
\end{abstract}

Palavras-chave: Passiflora edulis f. flavicarpa Deg., produtividade, insumo orgânico

\section{Production and mineral composition of yellow passion fruit in soil with "supermagro" biofertilizer and potassium}

\begin{abstract}
An experiment was carried out during the period from December, 2005 to July, 2006, in municipality of Remígio, Paraíba, Brazil, in order to evaluate the effects of the biofertilizer "supermagro" applied to soil in liquid form diluted in water in a ratio of 1:4, 30 days before and at intervals of 90 days after planting in absence and presence of potassium applied 60 days after planting and every 60 days subsequently until harvest on the production and mineral nutrition of yellow passion fruit plants (Passiflora edulis f. flavicarpa Deg.) The treatments were distributed in randomized blocks using the factorial design $5 \times 2$ referring to biofertilizer levels: $0,1,2,3$ and $4 \mathrm{~L} \mathrm{plant}^{-1}$ in absence and presence of potassium at a $\mathrm{K}_{2} \mathrm{O}$ level of $20 \mathrm{~g} \mathrm{plant}^{-1}$. The soil of the experimental area is a Neossoil. The fruits were harvested daily for evaluation of fruit number per plant, mass of fruit, individual production per plant and productivity. The plants in the initial fructification phase were adequately provided with $\mathrm{N}, \mathrm{K}, \mathrm{S}, \mathrm{B}$, and $\mathrm{Zn}$, but they were deficient in $\mathrm{P}, \mathrm{Ca}, \mathrm{Mg}, \mathrm{Cu}, \mathrm{Fe}$ and $\mathrm{Mn}$. The mean mass of fruits was superior in plants of the treatments with biofertilizer and potassium, but the interaction biofertilizer "supermagro" versus potassium did not influence plant productivity.
\end{abstract}

Key words: Passiflora edulis f. flavicarpa Deg., productivity, organic manure

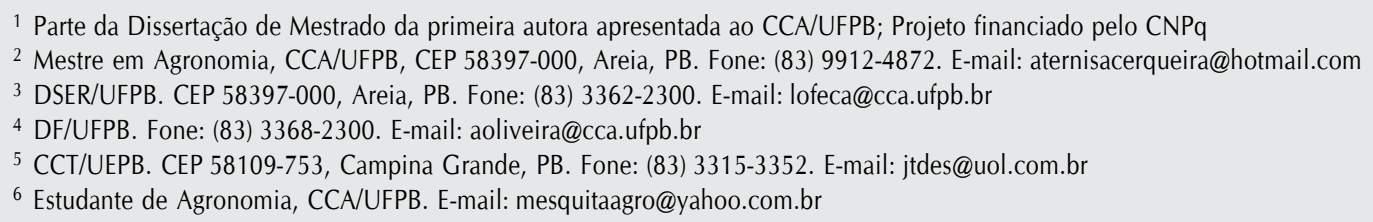




\section{INTRODUÇÃO}

A produção de frutas é, no Brasil, importante atividade do agronegócio com contribuição para o desenvolvimento econômico, tanto no mercado interno como na geração de divisas pela exportação de frutas frescas ou de seus produtos industrializados (Sá, 2005; Fernandes, 2006). Dentre as fruteiras cultivadas comercialmente, o maracujazeiro-amarelo (Passiflora edulis f. flavicarpa Dg.) se tem destacado nos últimos anos, sendo a espécie mais significativa do gênero Passiflora, em mais de 95\% dos pomares comerciais do Brasil (Negreiros et al., 2006).

Ressalta-se, dentre os fatores que contribuem para o aumento da produtividade do maracujazeiro-amarelo, a nutrição mineral das plantas; neste sentido, as adubações com nitrogênio e potássio são mais comuns, possivelmente em razão de não interferirem apenas no crescimento mas, também, no rendimento e na qualidade do produto colhido (Epstein \& Bloom, 2006).

O uso de biofertilizantes líquidos na forma de fermentados microbianos, simples ou enriquecidos, tem sido um dos processos empregados no controle das pragas e doenças e na composição mineral das plantas, estratégia baseada no equilíbrio nutricional e biodinâmico do vegetal. A maior importância do biofertilizante como fertilizante, não está nos quantitativos dos seus nutrientes, mas na diversidade da composição mineral, que pode formar compostos quelatizados e serem disponibilizados pela atividade biológica e como ativador enzimático do metabolismo vegetal (Prates \& Medeiros, 2001).

Apesar dos efeitos benéficos dos biofertilizantes enriquecidos quimicamente ao maracujazeiro-amarelo, aplicado via pulverização, como registrado por Icuma et al. (2000) e por Collard et al. (2001), Santos (2004) e Cavalcante et al. (2007) observaram que doses de supermagro diluído em água na razão de 1:1, quando fornecido ao solo em doses acima de 0,6 L planta ${ }^{-1}$, a cada 60 dias, inibiram o crescimento pelo diâmetro caulinar e a capacidade produtiva da cultura, comportamento verificado através de emissão de sintomas de toxicidade por necrose das folhas mais jovens, quando as plantas estavam com 70 dias após o plantio.

Observa-se nas sugestões de adubação, uma variação muito grande das dosagens recomendadas em função das diferentes condições climáticas das regiões produtoras, manejo da cultura e calendário sistemático de aplicação de fertilizantes. A ordem decrescente das exigências nutricionais no maracujazeiro-amarelo no Estado de São Paulo, conforme Malavolta et al. (1997) é: $\mathrm{N}>\mathrm{K}>\mathrm{Ca}>\mathrm{P}>\mathrm{Mg}>\mathrm{S}$ para os macronutrientes e $\mathrm{Mn}>\mathrm{Fe}>\mathrm{B}>\mathrm{Zn}>\mathrm{Cu}$ para os micronutrientes; no Estado da Paraíba a seqüência dos macronutrientes é basicamente a mesma mas, em geral, se registram amplitudes marcantes quanto aos micronutrientes (Gondim, 2003; Santos, 2004; Dantas et al., 2006a; Mesquita et al., 2006).

O potássio é o elemento de maior mobilidade na planta e passa de uma célula para outra e do xilema para o floema, razão porque é o componente mineral de maior expressão nos processos osmóticos que envolvem absorção e armaze- namento de água pelas plantas (Pimentel, 2004). A deficiência de $K$ no maracujazeiro-amarelo provoca redução no tamanho dos frutos e na área foliar, comprometendo a fotossíntese nas plantas e o conteúdo de sólidos solúveis nos frutos (Borges et al., 2003).

No tocante à diagnose nutricional do maracujazeiro amarelo, em diferentes estágios fenológico Carvalho et al. (2006) não constataram, no Estado do Rio de Janeiro, diferenças significativas entre os teores médios de macro e micronutrientes em relação ao estágio fenológico da cultura.

Ao estudarem os efeitos de doses de N, P e K em Latossolo Amarelo franco-argilo-arenoso, com $2 \mathrm{mg} \mathrm{kg}^{-1}$ de P e $78 \mathrm{mg} \mathrm{kg}^{-1}$ de K, Borges et al. (2002), não obtiveram efeitos na produtividade nem sobre os teores de $\mathrm{N}$ e $\mathrm{P}$ nas folhas; no entanto, notaram que o aumento das doses de $\mathrm{K}$ no solo elevou, os teores do nutriente nas folhas.

Avaliando os efeitos das doses de potássio aos níveis de 0 , 10, 15, 20 e 25 g planta $^{-1}$ de $\mathrm{K}_{2} \mathrm{O}$ fornecidos a cada 60 dias, no solo sem e com biofertilizante bovino diluído em água na razão de 1:4, aplicado ao nível de $15 \mathrm{~L} \mathrm{~m}^{2}$ a cada 120 dias após o plantio, Mesquita et al. (2006) constataram que no início da frutificação as plantas sem o biofertilizante estavam adequadamente supridas em N, K, B, Cu e Zn e, ainda, que nos tratamentos com insumo orgânico as plantas estavam deficientes em P, Ca, Mg, Fe e Mn, respectivamente.

Propôs-se, com este estudo, avaliar a ação do biofertilizante supermagro aplicado ao solo na forma líquida, na ausência e presença de potássio, sobre a produção e nutrição mineral do maracujazeiro-amarelo.

\section{MATERIAL E MÉTODOS}

O experimento foi desenvolvido no período de dezembro/ 2005 a julho/2006, no município de Remígio, PB, localizado a $6^{\circ} 53^{\prime} 00^{\prime \prime}$ de altitude Sul, $36^{\circ} 02^{\prime}$ '00” a Oeste do meridiano de Greenwich e a altitude de $470 \mathrm{~m}$ acima do nível do mar.

O clima do município é do tipo As’, que significa quente e úmido, com variação de temperatura e umidade relativa do ar entre 24,5 e $25{ }^{\circ} \mathrm{C}$, 70 e $80 \%$ respectivamente; as pluviosidades nos anos de 2005 e 2006, no local do experimento, foram 703 e $643 \mathrm{~mm}$, respectivamente.

O solo da área experimental foi classificado como Cambissolo Húmico Aluminoférrico léptico. A fertilidade na camada de 0-40 cm é deficiente em fósforo e matéria orgânica; possui teores médios de potássio, cálcio, magnésio e baixos de sódio e hidrogênio mais alumínio (Tabela 1); fisicamente, o solo é de textura arenosa na mesma profundidade, em que os atributos são indicados na Tabela 1. As variáveis de natureza química referentes à fertilidade do solo foram determinadas empregando-se a metodologia sugerida pela EMBRAPA (1997); as de natureza física, como densidade do solo, pelo método do torrão parafinado, densidade de partícula pelo método do balão volumétrico com água fervente e as frações de areia, silte e argila, pelo método do hidrômetro de Bouyoucos, conforme descrito em Black (1965). 
Tabela 1. Valores de alguns atributos físicos e químicos* do solo (profundidade de 0 - $40 \mathrm{~cm}$ ) antes da instalação dos tratamentos

\begin{tabular}{|c|c|c|c|c|c|c|c|c|c|c|c|}
\hline \multicolumn{12}{|c|}{ Atributos químicos } \\
\hline \multirow[b]{2}{*}{$\mathrm{pH}\left(\mathrm{H}_{2} \mathrm{O}_{1: 2,5}\right)$} & \multirow{2}{*}{$\begin{array}{c}\text { M.O } \\
\text { g dm }{ }^{-3}\end{array}$} & $\mathbf{P}$ & & & $\mathrm{Ca}^{+2}$ & $\mathrm{Mg}+2$ & $\mathrm{Na}^{+}$ & $\mathrm{H}^{+}+\mathrm{Al}^{3+}$ & $\mathrm{Al}^{3+}$ & CTC & \multirow{2}{*}{ V\% } \\
\hline & & \multicolumn{3}{|c|}{$\mathrm{mg} \mathrm{dm}^{-3}$} & \multicolumn{6}{|c|}{$\mathrm{cmol}_{\mathrm{c}} \mathrm{dm}^{-3}$} & \\
\hline 6,48 & 12,54 & 8,16 & & & 2,45 & 0,70 & 0,025 & 1,23 & 0,00 & 4,51 & 72,55 \\
\hline \multicolumn{12}{|c|}{ Atributos físicos } \\
\hline AMG & AG & AM & $\mathrm{AF}$ & AMF & Silte & Argila & Ada & GF & Ds & Dp & \multirow{2}{*}{$\begin{array}{c}\mathrm{Pt} \\
\left(\mathrm{m}^{3} \mathrm{~m}^{-3}\right)\end{array}$} \\
\hline \multicolumn{8}{|c|}{$\left(g^{~ k g-1}\right)$} & $\%$ & \multicolumn{2}{|c|}{$\left(\mathrm{g} \mathrm{cm}^{-3}\right)$} & \\
\hline 119 & 134 & 210 & 248 & 289 & 125 & 89 & 38 & 57 & 1,57 & 2.65 & 0,41 \\
\hline
\end{tabular}

* M.0 - Matéria orgânica; CTC - Capacidade de troca catiônica - $\left[\mathrm{Ca}^{2+}+\mathrm{Mg}^{2+}+\mathrm{Na}^{+}+\mathrm{K}^{+}+\left(\mathrm{H}^{+}+\mathrm{Al}^{3+}\right)\right]$; V - Saturação por bases $-\left(\mathrm{Ca}^{2+}+\mathrm{Mg}^{2+}+\mathrm{Na}^{+}+\mathrm{K}^{+} / \mathrm{CTC}\right) \times 100$; $\mathrm{AMG}-\mathrm{Areia} \mathrm{muito}^{2}$ grossa; AG - Areia grossa; AM - Areia média; AF - Areia fina; AMF - Areia muito fina; Ada - Areia dispersa em água; GF - Grau de floculação; Ds - Densidade do solo; Dp - Densidade de partícula; $\mathrm{Pt}$ - Porosidade total

As covas foram abertas nas dimensões 0,4 x 0,4 x 0,4 m e preenchidas com material de solo dos primeiros $10 \mathrm{~cm}$, juntamente com $5 \mathrm{~L}$ de esterco bovino de relação $\mathrm{C} / \mathrm{N}=17: 1$. Os tratamentos foram dispostos em blocos casualizados, em dezembro de 2005, com três repetições e nove plantas por parcela, adotando-se o arranjo fatorial $5 \times 2$ referente aos volumes do biofertilizante supermagro (enriquecido com macro, micronutrientes e mistura protéica), diluído em água na razão de $1: 4$, equivalente a $20 \%$ do insumo em cada dose aplicada: 0, 1, 2, 3 e $4 \mathrm{~L}_{\text {planta }}{ }^{-1}$ da mistura, na ausência e presença de potássio, aos teores de 20 g planta $^{-1}\left(\mathrm{~K}_{2} \mathrm{O}\right)$, na forma do cloreto de potássio $\left(56 \%\right.$ de $\left.\mathrm{K}_{2} \mathrm{O}\right)$. O supermagro foi aplicado 30 dias antes do plantio e a cada 90 dias após até o final do experimento e o potássio 30 dias após o plantio e a cada 60 dias até a colheita; depois de preparado o biofertilizante supermagro, apresentava na matéria seca, os teores de 1,43, 0,26, 1,01, 0,49, 0,26, 1,07 $\mathrm{g} \mathrm{kg}^{-1}$ de $\mathrm{N}, \mathrm{P}$, K, Ca, Mg e S; 439, 332, 155, 961, 1699 e $328 \mathrm{mg} \mathrm{kg}^{-1}$ de $\mathrm{B}, \mathrm{Cu}, \mathrm{Fe}, \mathrm{Mn}, \mathrm{Zn}$ e Na, respectivamente com pH 4,6 e condutividade elétrica $13,18 \mathrm{dS} \mathrm{m}^{-1}$.

O plantio das mudas de maracujazeiro-amarelo (Passiflora edulis f. flavicarpa Deg.) foi feito em 05/12/2005, no espaçamento de $2 \mathrm{~m}$ entre linhas e de $3 \mathrm{~m}$ entre plantas nas linhas. Utilizou-se para sustentação das plantas, espaldeira com um arame liso $\mathrm{n}^{\circ} 12$ instalado no topo das estacas, com altura de 2,2 m. Para a condução das plantas até o arame, foi utilizado um tutor e, quando as plantas atingiram 10 ou $15 \mathrm{~cm}$ acima da espaldeira, podou-se a gema apical para emissão dos ramos laterais.

O supermagro foi produzido por fermentação anaeróbica de $30 \mathrm{~L}$ de esterco fresco de bovino, juntamente com macro e micronutrientes e uma mistura protéica em 200 L de água não salina em recipiente não oxidável com capacidade para 240 L (Meirelles et al., 1997). A mistura protéica (MP) era constituída de $1 \mathrm{~L}$ de leite, $1 \mathrm{~L}$ de melaço, $100 \mathrm{~mL}$ de sangue, $100 \mathrm{~g}$ de fígado de bovino, $200 \mathrm{~g}$ de farinha de osso e $200 \mathrm{~g}$ de fosfato natural em pó. Inicialmente, misturaram-se $20 \mathrm{~L}$ de esterco bovino em $100 \mathrm{~L}$ de água e, em seguida, se adicionaram os componentes químicos e a mistura protéica, na seguinte ordem: $2 \mathrm{~kg}$ de sulfato de zinco + MP, $300 \mathrm{~g}$ de sulfato de manganês + MP, $300 \mathrm{~g}$ de sulfato de ferro + MP, $300 \mathrm{~g}$ de sulfato de cobre + MP, $2 \mathrm{~kg}$ de cloreto de cálcio + MP, 1 kg de ácido bórico + MP, 2 kg de sulfato de magnésio + MP, $50 \mathrm{~g}$ de sulfato de cobalto + MP, $100 \mathrm{~g}$ de molibdato de sódio + MP. Após serem adicionados os primei- ros quatro componentes, misturaram-se mais $10 \mathrm{~L}$ de esterco fresco e se completou o volume com água, para 200 L. Ao adicionar todos os constituintes no intervalo de 30 dias, manteve-se o sistema em fermentação anaeróbica por mais 30 dias para então se proceder a diluição em água e a aplicação no solo. Para manutenção do sistema isento de oxigênio, conectou-se uma das extremidades de uma mangueira fina na base superior do biodigestor e a outra permaneceu imersa em um recipiente com água.

Fez-se a irrigação por gotejamento instalando-se, em cada planta, dois emissores tipo catife auto-compensante, com vazão de 3,75 L h-1 e pressão de serviço $2 \mathrm{MPa}$, fornecendose diariamente a cada planta, nos primeiros 60 dias, $2 \mathrm{~L}$, dos 60-90 dias, $4 \mathrm{~L}$, e a partir da floração $10 \mathrm{~L}_{\text {planta }}{ }^{-1} \mathrm{dia}^{-1}$ de água adequada para a irrigação do tipo $\mathrm{C}_{1} \mathrm{~S}_{1}$, de condutividade elétrica $=0,33 \mathrm{dS} \mathrm{m}{ }^{-1}$ e RAS $=2,72\left(\operatorname{mmol}_{\mathrm{C}} \mathrm{L}^{-1}\right)^{0,5}$, conforme sugestão de Gondim (2003).

No início da frutificação das plantas se obtiveram amostras da $3^{\mathrm{a}}$ ou $4^{\mathrm{a}}$ folha, a partir do broto terminal dos ramos sadios intermediários entre as extremidades, para determinação dos teores de macro e micronutrientes na matéria seca, conforme Malavolta et al. (1997). Coletaram-se 12 folhas de cada planta em nove plantas, totalizando 108 folhas por tratamento.

A colheita foi realizada diariamente, durante quatro meses, no período de abril a julho de 2006 retirando-se, das plantas, os frutos, no início da maturação, com aproximadamente $20 \%$ do seu volume com coloração amarela (Aular, 1995) os quais, quando colhidos, eram armazenados em caixas tipo K; semanalmente os frutos eram contados e pesados para obtenção do número de frutos por planta, massa média de frutos, produção por planta e produtividade, no final do experimento.

Os resultados foram submetidos à análise de variância pelo Teste F e regressão polinomial (Ferreira, 2000).

\section{RESULTADOS E DISCUSSÃO}

A interação supermagro versus potássio, exceto sobre a massa média dos frutos, não exerceu efeitos significativos quanto ao número de frutos colhidos, a produção por planta e a produtividade, mas, conforme indicado na Tabela 2, os respectivos componentes da produção foram influenciados pelas doses do supermagro aplicado ao solo. 
Tabela 2. Resumo das análises de variância, referentes ao número de frutos (Nf); massa média de frutos (MMf); produção por planta (Pp) e produtividade (Pt) do maracujazeiro-amarelo em função da aplicação de diferentes doses de supermagro na ausência e presença de potássio no solo

\begin{tabular}{lccccc}
\hline \multirow{2}{*}{ Fontes de variação } & \multirow{2}{*}{ GL } & \multicolumn{4}{c}{ Quadrado médio } \\
\cline { 4 - 6 } & & $\mathbf{N f}$ & \multicolumn{1}{c}{ MMf } & Pp & Pt \\
Blocos & 2 & $3211,60^{\text {NS }}$ & $279,31^{\text {NS }}$ & $123,62^{* *}$ & $334,60^{* *}$ \\
Doses de Supermagro (S) & 4 & $434,36^{*}$ & $212,26^{\text {NS }}$ & $21,26^{*}$ & $55,40^{*}$ \\
Doses de Potássio (K) & 1 & $17,63^{\text {NS }}$ & $59,08^{\text {NS }}$ & $2,72^{\text {NS }}$ & $1,65^{\text {NS }}$ \\
S x K & 4 & $153,97^{\text {NS }}$ & $889,22^{* *}$ & $1,26^{\text {NS }}$ & $7,44^{\text {NS }}$ \\
Resíduo & 18 & 146,12 & 237,84 & 4,78 & 13,19 \\
Total & 29 & 11424,30 & 9304,72 & 425,85 & 1159,60 \\
CV (\%) & & 13,94 & 8,52 & 13,95 & 13,76 \\
\hline
\end{tabular}

NS - Não significativo; $\left(^{*}\right)$ e $\left(^{* \star}\right)$ respectivamente significativos a níveis de 5 e $1 \%$ de probabilidade pelo Teste $\mathrm{F}$

O número de frutos colhidos por planta em função das doses de supermagro, não se ajustou a nenhum modelo de regressão. Os valores entre os tratamentos oscilaram de 80 a 96 frutos por planta, resultando em valor médio geral de 86,6 frutos planta $^{-1}$. Esses resultados, embora inferiores aos 139 frutos planta $^{-1}$ de Collard et al. (2001) em plantio pulverizado mensalmente com agrobio na concentração de $2 \%$ em água, superaram a variação de 32 a 38 frutos planta $^{-1}$ obtidos por Santos (2004) e de 52 a 65 frutos por planta ${ }^{-1}$ registrada por Dantas et al. (2006b) em solo tratado com supermagro diluído em água, na razão de 1:1 (50\%) e de 1:4 (20\%), aplicados a cada 60 e 90 dias, respectivamente, após o plantio. A superioridade dos dados de Collard et al. (2001) evidencia maior eficiência do insumo aplicado à cultura por via foliar comparado ao seu fornecimento diretamente no solo. Ao se considerar a complexidade química do supermagro conclui-se que, possivelmente, sua aplicação no solo aumenta a disponibilidade de alguns nutrientes, como cloreto em níveis elevados, a ponto de a aplicação promover a toxicidade e capaz de reduzir a capacidade produtiva do maracujazeiro-amarelo. A inferioridade dos valores de Santos (2004) em relação aos dados em apreço, deve ser uma resposta da maior concentração e maior freqüência de aplicação do supermagro no solo. Conforme o autor, a fertilização do solo com supermagro na concentração de 1:1 ou $50 \%$ com freqüência de 60 dias após o plantio provoca, toxicidade no maracujazeiro-amarelo, a partir dos 70 dias de idade das plantas.

A massa média dos frutos aumentou nos tratamentos com 3 e $4 \mathrm{~L}_{\text {planta }}{ }^{-1}$ do supermagro no solo com $\mathrm{K}_{2} \mathrm{O}$ e decresceu no solo sem $\mathrm{K}_{2} \mathrm{O}$ com o aumento das doses do insumo orgânico (Figura 1); os dados aumentaram com amplitude de 196 a 210 g, nos tratamentos com e diminuíram de 189 a 152 g sem $\mathrm{K}_{2} \mathrm{O}$, mas em ambas as situações os valores são adequados ao mercado de frutas ao natural, que exige frutos de massa média entre 170 e 210 (Dantas et al., 2006a). O declínio da massa dos frutos com o aumento das doses do insumo no solo sem $\mathrm{K}_{2} \mathrm{O}$ pode estar associado ao aumento da população de microrganismos, em função do aumento das doses do supermagro e, em conseqüência, aumento do consumo de nutrientes, como potássio que, dentre os macronutrientes, é o mais transferido das folhas para os frutos (Malavolta et al., 1997).

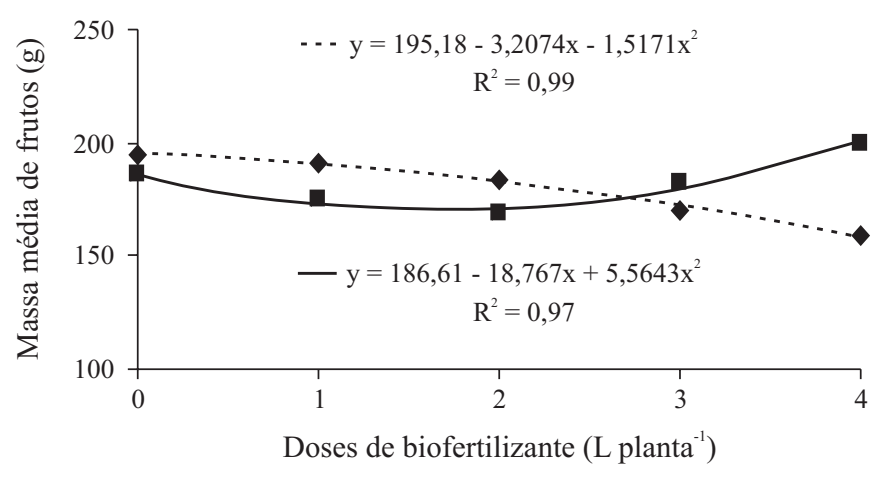

Figura 1. Massa média de frutos do maracujazeiro-amarelo em função das doses de supermagro na ausência (- $\bullet$-) e presença (- - ) de potássio aplicado ao solo

A interação supermagro versus potássio, não interferiu na produção por planta nem na produtividade da cultura mas as doses do insumo orgânico exerceram efeitos sobre as respectivas variáveis. Os dados não se adequaram a nenhum tipo de regressão e foram superiores nos tratamentos sem adição do supermagro (0 L planta-1 ${ }^{-1}$. Os valores médios da produção por planta e da produtividade foram 15,66 kg planta-1 e 26,11 t ha-1 . Os dados médios da produção por planta e produtividade foram: 18,2, 14,8, 14,2, 16,2 e 14,2 kg planta-1 e da produtividade $30,5,25,1,23,5,27,8$ e $23,7 \mathrm{t} \mathrm{ha}^{-1}$ nas doses do supermagro 0, 1, 2, 3 e $4 \mathrm{~L}_{\text {planta }}{ }^{-1}$, respectivamente. Este comportamento foi também registrado por Santos (2004), Dantas et al. (2006a), Macêdo et al. (2006) e Cavalcante et al. (2007) ao constatarem que a aplicação do supermagro nas freqüências de 60 e de 90 dias inibiu a capacidade produtiva do maracujazeiro-amarelo. O elevado número de componentes químicos e suas respectivas quantidades empregadas na produção do insumo podem ter provocado ação tóxica às plantas, com reflexos negativos na produção.

Mesmo se constatando que o supermagro inibiu a capacidade produtiva do maracujazeiro-amarelo, a produtividade foi superior à média nacional de $13,38 \mathrm{t} \mathrm{ha}^{-1} \mathrm{e}$ nordestina de 10,86 t ha'-1; foi superior, também, aos dados produzidos nas regiões Norte e aos valores médios de 24,35, 17,22, 14,37 e 14,27 t ha-1, respectivamente, nos Estados do Espírito Santo, São Paulo, Minas Gerais e Rio de Janeiro, sob cultivo convencional da cultura (IBGE, 2006). Comparativamente com plantios sob aplicação do supermagro, a produtividade foi superior aos $10,8 \mathrm{tha}^{-1}$ obtidos por Santos (2004), à variação de 16,8 a 21,4 t ha-1 apresentada por Dantas et al. (2006b) e de 11,2 a 17,3 t ha-1 por Macêdo et al. (2006). Com relação às plantas tratadas com biofertilizante comum ou simples (esterco fresco de bovino e água), a produtividade média foi superior aos $13,7 \mathrm{t} \mathrm{ha}^{-1}$ apresentados por Santos (2004) e 19,5 t ha-1, e Dantas et al. (2006a).

Os teores de nitrogênio aumentaram e diminuíram, respectivamente, com as doses de supermagro nos tratamentos sem e com potássio (Figura 2A). A redução dos valores nos tratamentos com $\mathrm{K}_{2} \mathrm{O}$ pode ter sido ocasionada pela interação antagônica entre o nitrogênio e o potássio, refletindo-se no declínio da acumulação de $\mathrm{N}$ pelas plantas em relação ao solo sem aplicação de potássio (Raij, 1991; Malavolta, 2006). 
Apesar da inferioridade dos conteúdos de $\mathrm{N}$ nas plantas com aplicação de $\mathrm{K}_{2} \mathrm{O}$ em relação aos tratamentos sem potássio, os valores se situaram na faixa de 40 a $50 \mathrm{~g} \mathrm{~kg}^{-1}$ e, conforme Malavolta et al. (1997) expressam que, no início da frutificação, o pomar estava adequadamente suprido em nitrogênio. Ao se considerar que aos 70 dias após o plantio todas as plantas estavam com aspectos sintomáticos de carência de nitrogênio, conclui-se que o fornecimento de $20 \mathrm{~g}$ de $\mathrm{N}$ por planta na forma de uréia corrigiu a deficiência e manteve o pomar equilibrado quanto a este nutriente, pelo menos até o início da frutificação, ocasião em que foi feita a coleta das folhas para avaliação do estado nutricional das plantas.

Os teores de fósforo não variaram com os níveis de supermagro aplicados, independente da adição ou não de $\mathrm{K}_{2} \mathrm{O}$; os valores não se adequaram a nenhum modelo de regressão e o teor médio foi de $3,33 \mathrm{~g} \mathrm{~kg}^{-1}$ indicado na Figura $2 \mathrm{~B}$, que está abaixo do limite crítico mínimo de $4 \mathrm{~g} \mathrm{~kg}^{-1}$ exigido pela cultura; quantitativamente, no início da frutificação as plantas se apresentavam deficientes em fósforo; ante esta constatação, a adição de fosfato natural ao supermagro não supriu adequadamente as exigências do maracujazeiro-amarelo em fósforo, em virtude, quiçá, desta inconveniência estar associada às interações entre o complexo químico existente no insumo orgânico, após ser aplicado ao solo.

No que se refere à ausência de interferência das fontes de variação adotadas em relação ao fósforo acumulado nas folhas, algumas das situações podem ter resultado nesta ausência de efeitos significativos: a) baixa atividade microbiana para a solubilização do fosfato natural e lenta liberação do nutriente; b) o período de 60 dias pode não ter sido suficiente para a fermentação da mistura esterco + água + componentes químicos para preparação do supermagro; c) o elevado número de compostos químicos e as grandes quantidades de alguns componentes podem ter resultado em uma mistura química pouca eficiente à fertilidade do solo e à nutrição das plantas.

A acumulação de potássio nas folhas foi estimulada pelo aumento nos valores de supermagro aplicados e pela adição de potássio ao solo. Conforme indicado na Figura 2C, nas plantas submetidas a dose máxima do insumo orgânico (4 L planta ${ }^{-1}$ ), os teores estavam compatíveis com os níveis mínimos exigidos pelo maracujazeiro-amarelo; verifica-se também, na referida Figura, que o emprego de $\mathrm{K}_{2} \mathrm{O}$ no solo elevou significativamente o teor de $\mathrm{K}$ nas folhas que, conforme Malavolta et al. (1997) varia de 30 a $35 \mathrm{~g} \mathrm{~kg}^{-1}$ de matéria seca foliar.

Referente ao cálcio, os teores na matéria seca foliar nas plantas dos tratamentos sem $\mathrm{K}_{2} \mathrm{O}$ aumentaram de 3,92 até o valor máximo estimado de $6,78 \mathrm{~g} \mathrm{~kg}^{-1}$ entre as doses 0,0 e 2,0 L planta $^{-1}$ de supermagro; por outro lado, a adição de potássio inibiu a acumulação de cálcio nas folhas do maracujazeiro, com teor médio entre as doses do insumo orgânico de 5,61 $\mathrm{g} \mathrm{kg}^{-1}$ de matéria seca (Figura 2D).

A tendência dos resultados na presença de $\mathrm{K}_{2} \mathrm{O}$ apresenta-se em acordo com a observada por Santos (2004) ao concluir que a adição de supermagro no solo a cada 60 dias, nos níveis de $0,0,0,6,1,2$, 1,8, e 2,4 L planta $^{-1}$, aumentou os valores de cálcio nas folhas de maracujazeiro-amarelo de 8,5 para até $15,4 \mathrm{~g} \mathrm{~kg}^{-1}$, na dose de $2 \mathrm{~L}$ planta $^{-1}$ e em seguida
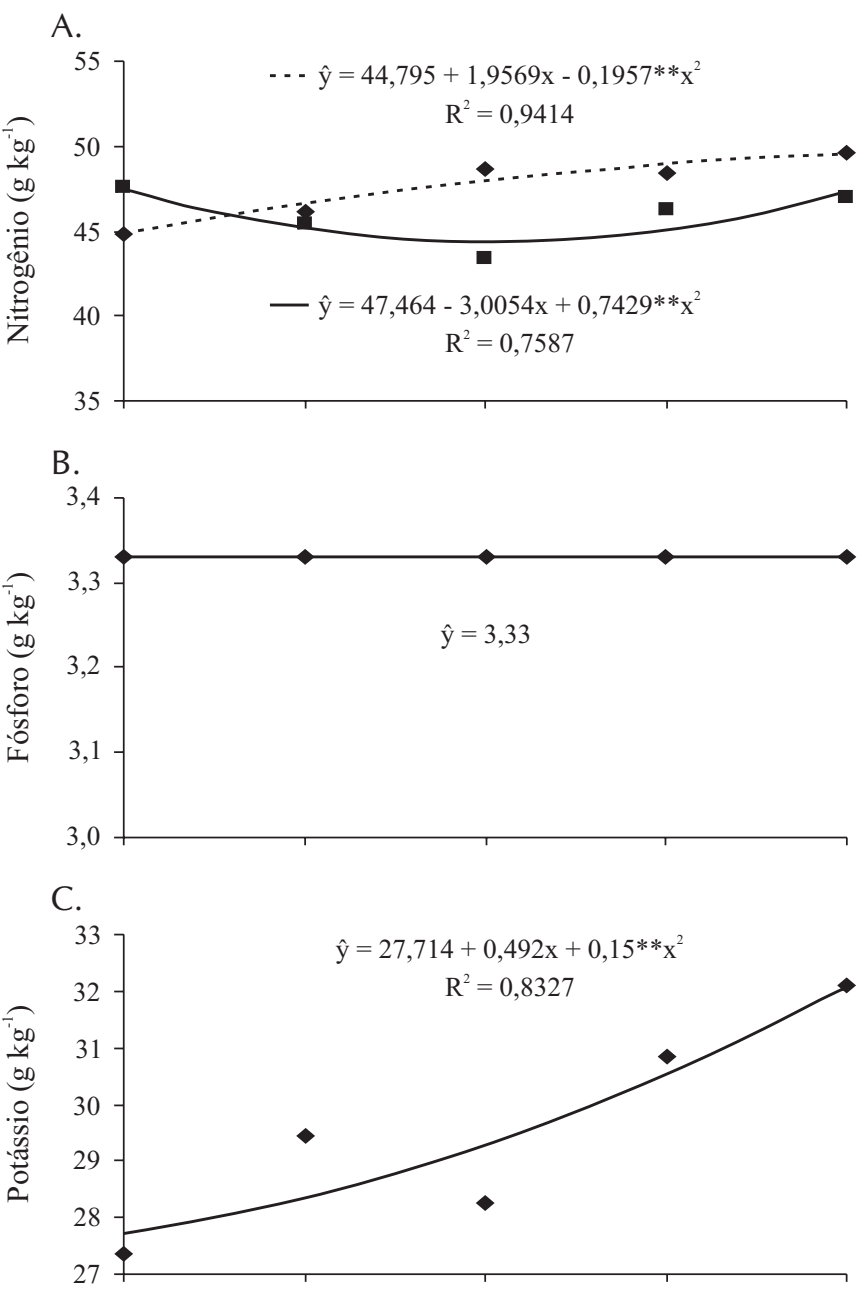

D.
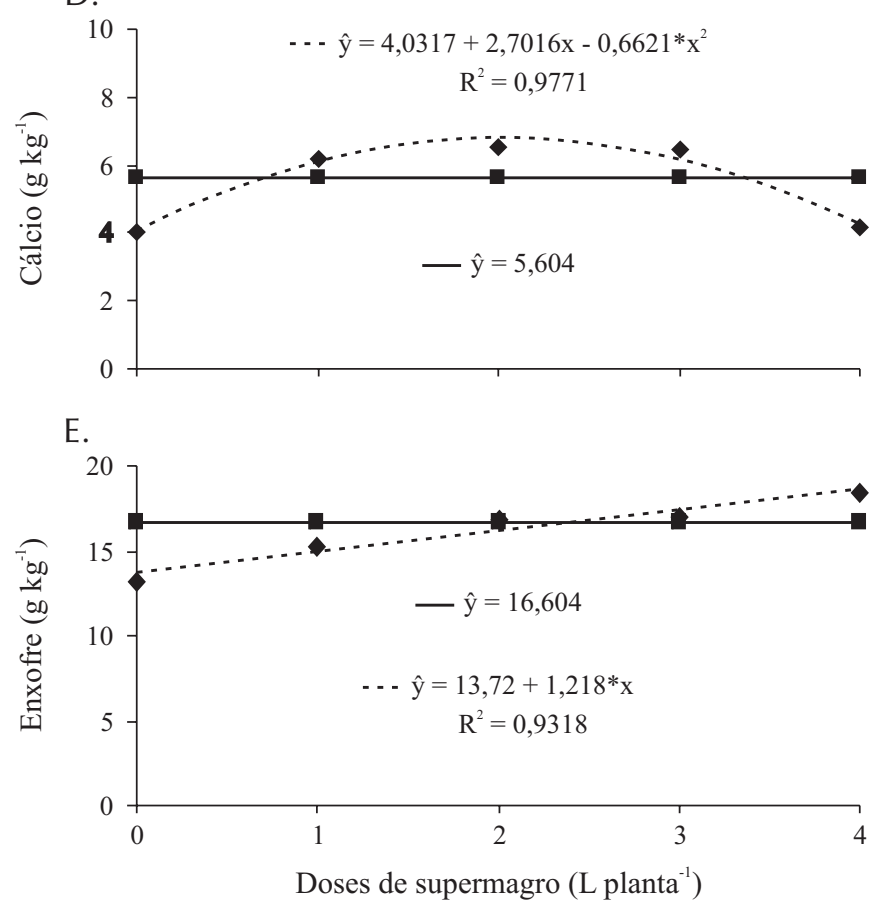

Figura 2. Teores foliares médios de nitrogênio (A), fósforo (B), potássio $(C)$, cálcio (D) e enxofre (E) nas folhas de maracujazeiro-amarelo em função das doses de supermagro na ausência (- - ) e presença (--) de $\mathrm{K}_{2} \mathrm{O}$ aplicados ao solo 
ocorreu o declínio; entretanto, os dados em apreço foram marcadamente inferiores aos de Santos (2004); os resultados são indicativos de que o pomar estava, por ocasião da amostragem, com carência de cálcio, uma vez que os teores exigidos pela cultura se situam na amplitude de 15 a $20 \mathrm{~g} \mathrm{~kg}^{-1}$ de matéria seca foliar (Malavolta et al., 1997).

A acumulação de magnésio não foi influenciada pelas fontes de variação e os valores não se ajustaram a nenhum modelo matemático, e os dados aumentaram de 2,92 g kg-1 na dose $0 \mathrm{~L}_{\text {planta }}{ }^{-1}$ de supermagro para até $4,02 \mathrm{~g} \mathrm{~kg}^{-1}$ na dose de $4 \mathrm{~L}_{\text {planta }}{ }^{-1}$; este aumento foi resposta da adição do sulfato de magnésio na preparação do insumo e expressa que apenas a dose máxima liberou o macronutriente em nível adequado ao maracujazeiro-amarelo (Malavolta et al., 1997).

Detectou-se com referência ao enxofre, diferença significativa entre os níveis de supermagro aplicados no solo sem e com $\mathrm{K}_{2} \mathrm{O}$; já nos tratamentos com potássio os dados não se adequaram a nenhum modelo de regressão com valores médios entre as doses de supermagro de $16,64 \mathrm{~g} \mathrm{~kg}^{-1}$; na ausência de $\mathrm{K}_{2} \mathrm{O}$ os valores aumentaram linearmente de $1,218 \mathrm{~g} \mathrm{~kg}^{-1}$ para cada aumento unitário do supermagro aplicado, atingindo teor máximo de 18,46 g kg-1 (Figura 2E); referidos valores se apresentam superiores à faixa de 3 a $4 \mathrm{~g} \mathrm{~kg}^{-1}$ do macronutriente admitido como adequado à cultura (Malavolta et al., 1997). A marcante superioridade é resposta da adição de enxofre na preparação do supermagro a partir da aplicação do sulfato de cobalto, cobre, ferro, magnésio, manganês e zinco, respectivamente.

Os valores de boro cresceram de 48 a $220 \mathrm{mg} \mathrm{kg}^{-1}$ com o aumento da adição do supermagro (Figura 3A) e de 100 para até $128 \mathrm{mg} \mathrm{kg}^{-1}$ nos tratamentos sem e com potássio, respectivamente; pelos valores, nota-se que no início da frutificação as plantas estavam com teores notadamente além da faixa de suprimento equilibrado de boro ao maracujazeiro-amarelo. Para Malavolta et al. (1997) a cultura está adequadamente suprida em boro com teores foliares entre 40 e $50 \mathrm{mg} \mathrm{kg}^{-1}$.

Quanto ao cobre, os teores nos tratamentos com potássio não sofreram grande variação, com valor médio de $6,51 \mathrm{mg} \mathrm{kg}^{-1}$. Nas plantas desenvolvidas no solo sem o fornecimento de $\mathrm{K}_{2} \mathrm{O}$, a acumulação de cobre aumentou de forma quadrática atingindo o maior valor de $7,26 \mathrm{mg} \mathrm{kg}^{-1}$ na dose estimada de 1,72 L planta ${ }^{-1}$ (Figura 3B); esses valores expressam que as plantas estavam deficientes desse micronutriente. A faixa admitida como adequada de cobre ao maracujazeiro-amarelo se situa na amplitude de 10 a $20 \mathrm{mg} \mathrm{kg}^{-1}$ (Malavolta et al., 1997).

Apesar da interação supermagro x potássio ter exercido ação significativa sobre os teores de Fe nas plantas, percebe-se que na ausência de potássio o aumento dos níveis do insumo orgânico prejudicou a acumulação do micronutriente nas plantas (Figura 3C), vez que os valores foram reduzidos de 128 para $98 \mathrm{mg} \mathrm{kg}^{-1}$ cujo declínio, possivelmente, seja promovido pelos elevados teores de fósforo no solo que exerce antagonismo sobre a disponibilidade de ferro (Padilla, 1998). As plantas dos tratamentos com $\mathrm{K}_{2} \mathrm{O}$ apresentaram grande variabilidade de valores com média de $99 \mathrm{mg} \mathrm{kg}^{-1}$; pelos resultados, constata-se que tanto na ausência como na presença de potássio a utilização do sulfato de ferro na preparação do supermagro não foi suficiente para disponibilizar Fe em nível suficiente às exigências da cultura. Para Malavolta et al. (1997) plantas de maracujazeiro-amarelo nutricionalmente equilibradas devem conter na matéria seca foliar, entre 120 e $200 \mathrm{mg} \mathrm{kg}^{-1}$ de ferro.

Os teores de zinco nos tratamentos com potássio aumentaram de forma quadrática até a dose estimada de 1,5 $\mathrm{L} \mathrm{planta}^{-1}$ de supermagro, referente ao maior valor $32,3 \mathrm{mg} \mathrm{kg}^{-1}$. Nas plantas dos tratamentos sem potássio, os resultados não se adequaram a qualquer modelo de regressão, com valor médio de 28,6 mg kg-1 correspondentes às
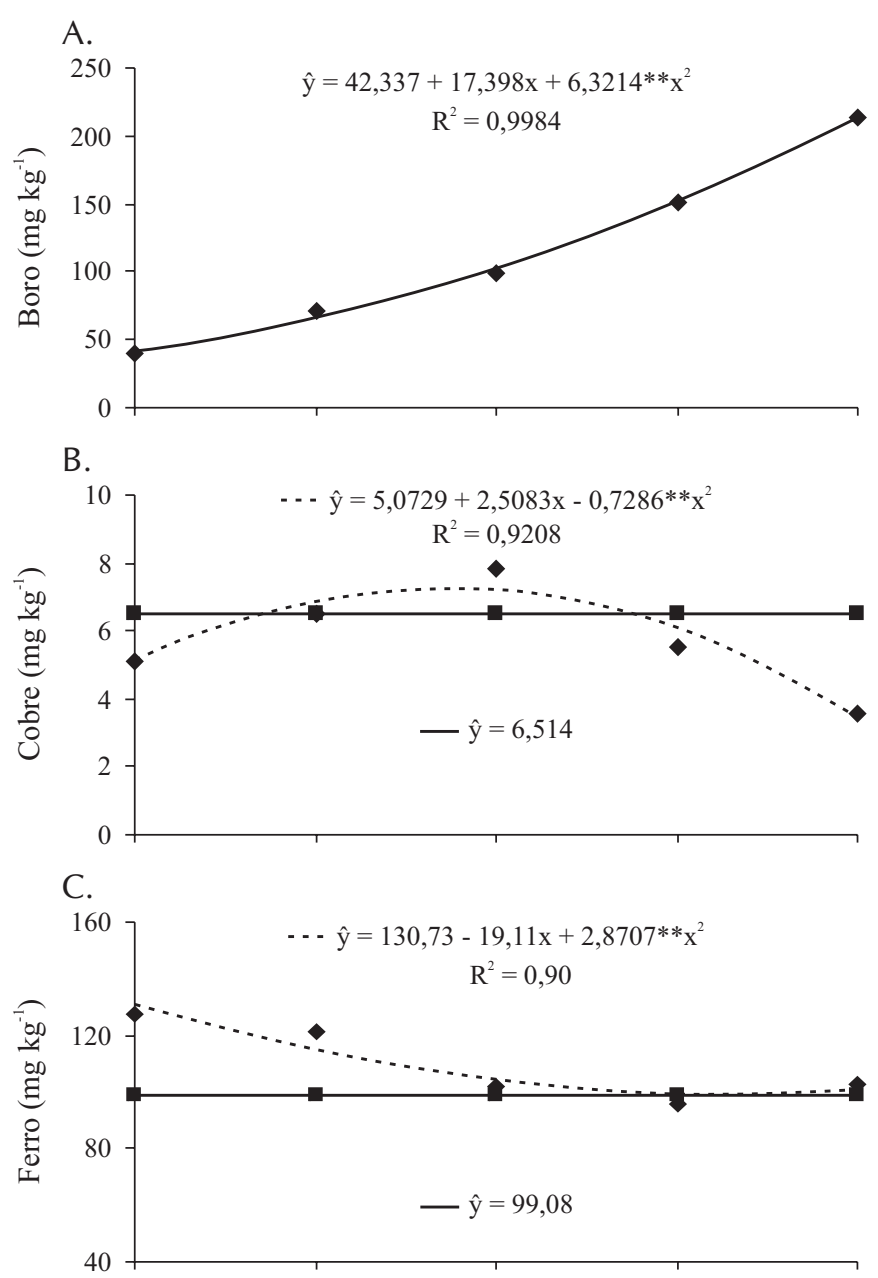

D.

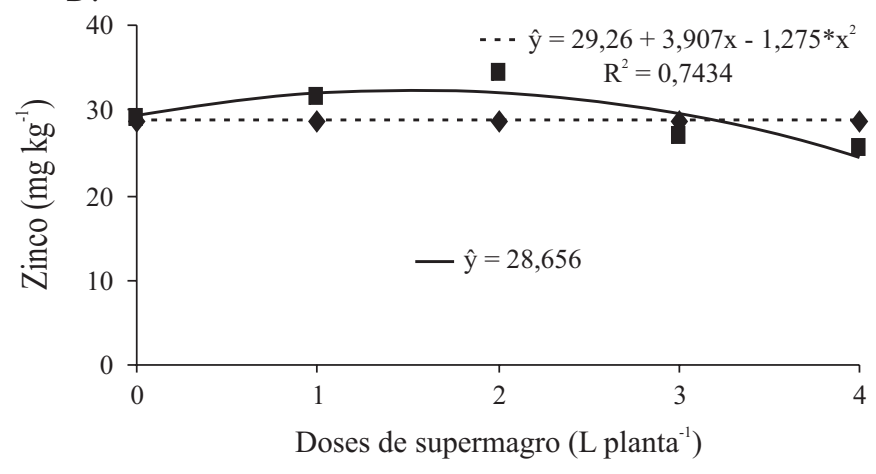

Figura 3. Teores foliares médios de boro $(A)$, cobre $(B)$, ferro $(C)$ e zinco (D) nas folhas de maracujazeiro-amarelo em função das doses de supermagro na ausência (-) e presença (-) de $\mathrm{K}_{2} \mathrm{O}$ aplicados ao solo 
doses de supermagro (Figura 3D); pelos resultados, no início da frutificação, as plantas estavam nutricionalmente equilibradas em zinco, que exigem, em média, de 25 a $40 \mathrm{mg} \mathrm{kg}^{-1}$ do micronutriente na matéria seca das folhas (Malavolta et al., 1997).

O manganês não sofreu interferência estatística da interação supermagro x potássio nem das fontes de variação isoladas. Os resultados médios, apesar de aumentarem de 129 para $170 \mathrm{mg} \mathrm{kg}^{-1}$, indicaram elevada dispersão (CV = 26,187\%) e, por isto, não se ajustaram a nenhum modelo de regressão. A exemplo do ferro, o emprego do sulfato de manganês para obtenção do supermagro não foi suficiente às exigências do maracujazeiro-amarelo, que oscila entre 400 e $600 \mathrm{mg} \mathrm{kg}^{-1}$ (Malavolta et al., 1997).

Quanto ao sódio, a adição de $\mathrm{K}_{2} \mathrm{O}$ resultou em menores teores nas folhas das plantas; esta inferência pode ser atribuída à competição com o sódio e o potássio, refletindo em menor absorção e translocação do elemento até as folhas; os dados, mesmo não se adequando a nenhum tipo de regressão com as doses de supermagro e apesar de não ser um micronutriente, os valores médios de 1730 e $1613 \mathrm{mg} \mathrm{kg}^{-1}$ nos tratamentos sem e com potássio foram excessivamente elevados em relação aos teores de boro, cobre ferro, manganês e zinco.

Ao se comparar os dados do presente trabalho com os de outros autores, como Santos (2004) e Rodolfo Júnior (2007), observou-se a mesma situação nutricional do maracujazeiro-amarelo para nitrogênio, cálcio, magnésio, enxofre, boro e manganês e que as plantas estavam adequadamente supridas em N, S, B e deficientes em P, Ca, Mg e Mn; nos demais nutrientes há diferenças entre as situações nutricionais das plantas.

Também se constatou que, exceto em potássio, as plantas dos dados em questão se apresentavam no mesmo estado nutricional que as cultivadas por Rodolfo Júnior (2007); esta semelhança pode ser resposta da diluição do supermagro em água ter sido a mesma de 1:4 ou 20\%, para ambos os casos, vez que os solos são basicamente de mesma natureza física e de mesmo potencial de fertilidade.

Com referência a Santos (2004) que usou a menor diluição do insumo em água, na razão de 1:1 ou 50\%, apenas promoveu maiores acumulações de cobre e ferro em relação aos presentes dados, e aos de Rodolfo Júnior (2007); situação que pode variar também com o tipo de solo, preparação das covas, época de plantio e manejo de cultura; expressa também, a necessidade de avaliações envolvendo a microbiologia do solo sob aplicação de insumos produzidos a partir de esterco bovino, como o supermagro, que deve conter substâncias húmicas. Para Nardi et al. (2002) é possível que as substâncias húmicas exerçam efeitos nas funções vitais das plantas e resultem, direta ou indiretamente, na absorção de íons e na nutrição mineral das plantas.

\section{CONCLUSÕES}

1. A massa média do fruto foi superior no solo com supermagro e potássio.
2. O supermagro não supriu as necessidades do maracujazeiro-amarelo em nitrogênio, fósforo, cálcio, magnésio, cobre, ferro e manganês.

3. O tamanho dos frutos pela massa média foi compatível com as exigências do mercado de frutas frescas.

\section{AGRADECIMENTOS}

Os autores agradecem ao Conselho Nacional de Desenvolvimento Científico e Tecnológico (CNPq) pelo financiamento do projeto e a oportunidade de incrementar recursos humanos na pesquisa.

\section{LITERATURA CITADA}

Aular, J. Características físicas del fruto y de la pulpa el julgo de la parchita según el estado de coloración. Bioagro, v.7, n.1, p.17-21, 1995.

Black, C. A. (ed.). Methods of soil analysis. Madison: American Society of Agronomy, 1965, Part.1, 22p.

Borges, A. L.; Caldas, R. C.; Lima, A. A.; Almeida, I. R. de. Efeito de doses de NPK sobre os teores de nutrientes nas folhas e no solo e na produtividade do maracujazeiro-amarelo. Revista Brasileira de Fruticultura, v.25, n.2, p.208-213, 2002.

Borges, A. L.; Rodrigues, M. G. V.; Lima. A. A.; Almeida, I. E.; Caldas, R. C. Produtividade e qualidade de maracujazeiro amarelo irrigado, adubado com nitrogênio e potássio. Revista Brasileira de Fruticultura, v.24, n.1, p.259-262, 2003.

Carvalho, A. J. C.; Fontes, P. S. F.; Monnerat, P. H.; Marinho, C. S.; Dutra, G. A. P.; Freitas, M. S. M. Diagnose nutricional do maracujazeiro amarelo em diferentes períodos fenológicos pelo método DRIS. In: Congresso Brasileiro de Fruticultura, 19, 2006, Cabo Frio. Resumos... Cabo Frio: SBF/ UENF/UFRRJ, 2006, p.519.

Cavalcante, L. F.; Santos, G. D. dos; Oliveira, F. A.; Cavalcante, I. H. L.; Gondim, S. C.; Beckman-Cavalcante, M. Z. Crescimento e produção do maracujazeiro-amarelo em solo de baixa fertilidade tratado com biofertilizantes líquidos. Revista Brasileira de Ciências Agrárias, v.2, n.1, p.15-19, 2007.

Collard, F. H.; Almeida, A.; Costa, M. D. R.; Rocha, M. C. Efeito do uso do biofertilizante Agrobio na cultura do maracujazeiro amarelo (Passiflora edulis f. flavicarpa Deg). Revista Biociências, v.7, n.1, p.15-21, 2001.

Dantas, T. A. G.; Cavalcante, L. F.; Santos, G. P.; Nascimento, J. A. M.; Mesquita, E. F.; Cavalcante, I. H. L. Teores foliares do maracujazeiro-amarelo em solo arenoso fertilizado com superfosfatos. In: Congresso Brasileiro de Fruticultura, 19, 2006, Cabo Frio. Resumos... Cabo Frio: SBF/UENF/ UFRRJ, 2006a, 547p.

Dantas, T. A. G.; Cavalcante, L. F.; Santos, G. P.; Nascimento, J. A. M.; Rodolfo Júnior, F.; Macêdo, J. P. S. Crescimento do maracujazeiro-amarelo em solo tratado com biofertilizante, NPK e calagem. In: Congresso Brasileiro de Fruticultura, 19, 2006, Cabo Frio. Resumos... Cabo Frio: SBF/UENFUFRRJ, 2006b, 547p. 
EMBRAPA - Empresa Brasileira de Pesquisa Agropecuária. Centro Nacional de Pesquisa de Solos. Manual de métodos de análise de solo. 2 ed., revisada. atualizada, Rio de Janeiro: CNPS.1997. 212p. Documentos, 1.

Epstein, E.; Bloom, J. Nutrição mineral de plantas. 2 ed. Londrina: Planta. 2006. 401p.

Fernandes, M. S. Perspectivas de mercado da fruta brasileira. Frutas do Brasil: saúde para o mundo. In: Congresso Brasileiro de Fruticultura, 19, 2006, Cabo Frio. Resumos... Cabo Frio: SBF/ UENF/UFRRJ, 2006. 8p.

Ferreira, P. V. Estatística experimental aplicado à agronomia. 3.ed. Maceió: UFAL. 2000. 604p.

Gondim, S. C. Comportamento do maracujazeiro-amarelo IAC 273/ $277+275$, em função do número de plantas por cova e lâminas de água. Areia: UFPB, 2003. 73p. Dissertação Mestrado

IBGE - Instituto Brasileiro de Geografia e Estatística. Levantamento sistemático da produção agrícola. <http://www.ibge.gov.br/>. 5 Jun. 2006.

Icuma, I. M.; Oliveira, M. A. S.; Alves, R. E. Efeito do uso de biofertilizante supermagro-agrobio na cultura do maracujazeiro amarelo (Passiflora edulis f. flavicarpa Deg.). In: Congresso Brasileiro de Fruticultura, 16, 2000, Fortaleza. Anais... Fortaleza: SBF, 2000. CD-Rom.

Macêdo, J. P. S.; Cavalcante, L. F.; Oliveira, F. A.; Sousa, G. B.; Dantas, T. A. G.; Mesquita, F. O. Produção de maracujazeiro-amarelo em função de biofetilizantes líquidos aplicados ao solo. In: Congresso Brasileiro de Fruticultura, 19, 2006, Cabo Frio. Resumos... Cabo Frio: SBF/UENFUFRRJ, 2006. 533p.

Malavolta, E. Manual de nutrição de plantas. São Paulo: Agronômica Ceres, 2006. 638p.

Malavolta, E.; Vitti, G. C.; Oliveira, S. A. Avaliação do estado nutricional das plantas: princípios e aplicações. Piracicaba: POTAFOS, 1997. 201p.

Meirelles, L. Bracagioli Neto, A.; Meirelles, A. L. Biofertilizantes enriquecidos: caminho sadio da nutrição e proteção das plantas. Porto Alegre: Ipê/CAE, 1997. 24p.
Mesquita, F. O.; Dantas, T. A. G.; Cavalcante, L. F.; Sousa, G. G.; Rodrigues, A. C.; Campos, V. B. Composição mineral do maracujazeiro-amarelo sobre adubação potássica, biofertilizante e cobertura do solo. In: Congresso Brasileiro de Fruticultura, 19, 2006, Cabo Frio. Resumos... Cabo Frio: SBF/ UENFUFRRJ, 2006, p.527.

Nardi, S.; Pizzeghello, D.; Muscolo, A.; Vianello, E. Physiological effects of humic substances on higher plants. Soil Biology \& Biochemistry, v.34, p.1527-1536, 2002.

Negreiros, J. R. da S.; Américo J. R. W.; Álvares, V. S.; Silva, J. O. C.; Nunes, E. S.; Alexandre, R. S.; Pimentel, L. D.; Bruckner, C. H. Influência do estádio de maturação e do armazenamento pós-colheita na germinação e desenvolvimento inicial do maracujazeiro-amarelo. Revista Brasileira de Fruticultura, v.28, n.1, p.21-24, 2006.

Padilla, W. Lo que usted desea saber del suelo su analisis e interpretación para fertirrigación. Quito: Governo Equatoriano, 1998. 121p.

Pimentel, C.A relação da planta com a água. Seropédica: Edur, 2004. 191p.

Prates, H. S.; Medeiros, M. B. de. "MB-4”. Entomopatógenos e biofetilizantes na citricultura orgânica. Campinas: SAA/ Coordenadoria de defesa Agropecuária. 2001. Folder

Raij, B. van. Geoquímica de micronutrientes. In: Ferreira, M. E.; Cruz, M. C. P. (Eds). Micronutrientes na Agricultura. Jaboticabal: POTAFOS/UNESP, 1991. Cap. 4, p.99-110.

Rodolfo Júnior, F. Biofertilizantes e adubação mineral no maracujazeiro-amarelo e na fertilidade do solo. Areia: UFPB, 2007. 83p. Dissertação Mestrado

Sá, J. R. Silício e cloreto de sódio na nutrição e produção de matéria seca do maracujazeiro - amarelo em solução nutritiva. Lavras: UFLA, 2005. 163p. Tese Doutorado

Santos, G. D. Avaliação do maracujazeiro-amarelo sob biofertilizantes aplicados ao solo na forma líquida. Areia: UFPB, 2004. 74p. Dissertação Mestrado 